\title{
Impact of improved cookstoves on women's and child health in low and middle income countries: a systematic review and meta-analysis
}

\author{
Megha Thakur, ${ }^{1}, 2$ Paulien A W Nuyts, ${ }^{3}$ Esther A Boudewijns, ${ }^{1}$ Javier Flores Kim, ${ }^{4}$ \\ Timor Faber, ${ }^{5,6}$ Giridhara R Babu, ${ }^{2}$ Onno C P van Schayck, ${ }^{1,4}$ Jasper V Been ${ }^{4,5,7}$
}

\begin{abstract}
- Additional material is published online only. To view please visit the journal online (http://dx.doi.org/10.1136/ thoraxinl-2017-210952).
\end{abstract}

${ }^{1}$ Care and Public Health Research Institute (CAPHRI), Maastricht University,

Maastricht, The Netherlands 2Public Health Foundation of India, Indian Institute of Public Health-Hyderabad, Bangalore, India

${ }^{3}$ Department of Public Health, Academic Medical Centre, University of Amsterdam, Amsterdam, The Netherlands ${ }^{4}$ Centre of Medical Informatics, Usher Institute of Population Health Sciences and Informatics, The University of Edinburgh, Edinburgh, UK

${ }^{5}$ Division of Neonatology, Department of Paediatrics, Erasmus MC-Sophia Children's Hospital, Rotterdam, The Netherlands

${ }^{6}$ Department of Public Health, Erasmus Medical Centre, Rotterdam, The Netherlands ${ }^{7}$ Department of Obstetrics and Gynaecology, Erasmus MCSophia Children's Hospital, Rotterdam, The Netherlands

Correspondence to Dr Onno C P van Schayck, Care and Public Health Research Institute (CAPHRI), Maastricht University, 6200 MD Maastricht, The Netherlands; onno.vanschayck@ maastrichtuniversity.n

MT and PAWN contributed equally.

Received 26 August 2017

Revised 7 May 2018

Accepted 28 May 2018

Published Online First

20 June 2018

\section{Check for updates}

To cite: Thakur M,

Nuyts PAW, Boudewijns EA, et al. Thorax

2018:73:1026-1040.

\begin{abstract}
Objectives Improved biomass cookstoves may help reduce the substantial global burden of morbidity and mortality due to household air pollution (HAP) that disproportionately affects women and children in low and middle income countries (LMICs).
\end{abstract}

Design Systematic review and meta-analysis of (quasi-) experimental studies identified from 13 electronic databases (last update: 6 April 2018), reference and citation searches and via expert consultation.

Setting LMICs

Participants Women and children

Interventions Improved biomass cookstoves

Main outcome measures Low birth weight (LBW), preterm birth, perinatal mortality, paediatric acute respiratory infections (ARIs) and COPD among women. Results We identified 53 eligible studies, including 24 that met prespecified design criteria. Improved cookstoves had no demonstrable impact on paediatric lower ARIs (three studies; 11560 children; incidence rate ratio $(\mathrm{IRR})=1.02(95 \% \mathrm{Cl} 0.84$ to 1.24$))$, severe pneumonia (two studies; 11061 children; IRR=0.88 (95\% CI 0.39 to 2.01$)$ ), LBW (one study; 174 babies; $\mathrm{OR}=0.74(95 \% \mathrm{Cl} 0.33$ to 1.66$))$ or miscarriages, stillbirths and infant mortality (one study; 1176 babies; risk ratio (RR) change $=15 \%(95 \% \mathrm{Cl}-13$ to 43$)$ ). No (quasi-)experimental studies assessed preterm birth or COPD. In observational studies, improved cookstoves were associated with a significant reduction in COPD among women: two studies, 9757 participants; $R R=0.74$ (95\% Cl 0.61 to 0.90). Reductions in cough (four studies, 1779 participants; $R R=0.72(95 \% \mathrm{Cl} 0.60$ to 0.87$)$ ), phlegm (four studies, 1779 participants; RR=0.65 (95\% CI 0.52 to 0.80$)$ ), wheezing/breathing difficulty (four studies; 1779 participants; RR=0.41 (95\% Cl 0.29 to 0.59)) and conjunctivitis (three studies, 892 participants; $\mathrm{RR}=0.58(95 \% \mathrm{Cl} 0.43$ to 0.78$))$ were observed among women.

Conclusion Improved cookstoves provide respiratory and ocular symptom reduction and may reduce COPD risk among women, but had no demonstrable child health impact.

Registration PROSPERO: CRD42016033075

\section{INTRODUCTION}

Solid biomass fuel is used as a primary cooking source by more than half of the world's population. ${ }^{1-3}$ About three-fourths of this use occurs in low and middle income countries (LMICs). ${ }^{1}$ The

\section{Key messages}

What is the key question?

- Pending the much-needed transition to using cleaner fuels, can improved cookstoves help reduce morbidity and mortality due to household air pollution (HAP) from biomass combustion among women and children in low and middle income countries?

What is the bottom line?

- Meta-analyses indicate that improved biomass cookstoves can decrease respiratory and ocular symptoms among women; no demonstrable impact on perinatal or child health was observed.

Why read on?

- This is the first meta-analysis assessing the health impact of improved cookstoves, providing valuable information for agenda setting to reduce the substantial global burden of morbidity and mortality from HAP.

combustion of biomass fuels results in pollutants such as carbon monoxide (CO) and particulate matter (PM), creating household air pollution (HAP) when produced inside. ${ }^{2}$ HAP results in a high burden of morbidity and mortality globally, disproportionately affecting LMICs. ${ }^{1-5}$ Globally, HAP was estimated to have caused 2.8 million deaths and 85.6 million disability-adjusted life years in 2015 . $^{4}$

In LMICs, women are traditionally at home taking care of the household, cooking and tending to the children, whereas men usually work during the day, away from home. Young children are often carried on their mothers' back while the latter carry out household chores inside. ${ }^{36}$ As a result, women and young children are particularly exposed to HAP from cooking and heating and are therefore at highest risk of developing HAP-associated adverse health conditions. ${ }^{2}$ Several studies have linked maternal exposure to biomass smoke during pregnancy to increased risks of stillbirth, preterm delivery, low birth weight (LBW) and other adverse health effects. $^{7-9}$ Exposure to biomass smoke furthermore increases the risk of respiratory infections among children and of COPD in adults. ${ }^{37}$ 
Switching the use of biofuels for cooking purposes towards clean(er) fuels such as liquefied petroleum gas, electricity or solar energy would be the preferred solution to reduce HAP and improve population health. ${ }^{31011}$ However, this transition is difficult in low income countries, due to lack of infrastructure, financial constraints and poor living conditions of households. ${ }^{1} 1011$ As a result, an estimated 1.8 billion people will still be reliant on solid biomass for cooking by $2040 .{ }^{1}$ It is therefore essential that alongside facilitating the transition to cleaner fuel options, other measures continue to be developed, tested and-when successful-implemented to reduce HAP from cooking using solid biomass. ${ }^{5}$ Such biomass cookstove improvements include, for example, adding chimneys and using better combustion centres to increase efficiency. Biomass cookstove improvements are currently more cost-effective than switching to cleaner fuels and may be the only affordable short-term solution to reduce HAP for billions of people living in LMICs. ${ }^{3} 1112$

Several studies have examined the effectiveness of improved biomass cookstoves in reducing HAP and improving health outcomes among its users, yielding seemingly inconsistent findings. ${ }^{3111314}$ Given the substantial global burden of death and disease associated with HAP and the significant contribution of biomass combustion-both current and projected-to this burden, a comprehensive assessment of the available evidence on the effectiveness of biomass fuel cookstove improvements in terms of health benefits is urgently needed. This will provide essential information to policy-makers to guide implementation of measures to reduce the burden from HAP associated with biomass combustion in LMIC areas where transition to cleaner fuels is not yet feasible. We conducted a comprehensive systematic review and meta-analysis to investigate the effectiveness of improved cookstoves to reduce adverse pregnancy outcomes and adverse health outcomes in women and children, as well as HAP exposure.

\section{METHODS}

\section{Protocol and registration}

The systematic review protocol is registered with PROSPERO (CRD42016033075) and can be accessed at http://www.crd.york. ac.uk/PROSPERO/display_record.asp?ID=CRD42016033075.

\section{Eligibility criteria}

Following Cochrane Effective Practice and Organisation of Care (EPOC) guidelines, ${ }^{15}$ we included randomised controlled trials (RCTs), non-randomised controlled trials (NRCTs) and quasi-experimental studies (ie, controlled before-after (CBA) studies and interrupted time-series studies) studying the impact of an improved biomass cookstove on pregnancy outcomes, child and/or women's health and/or exposure to HAP. We also identified any studies addressing the research question that had a longitudinal design but did not fit EPOC criteria. Studies were eligible when they were conducted in LMICs and included women aged 15-65 years and/or children aged 0-14 years. Any study in which more than $50 \%$ of the study population fulfilled these age criteria was included. From studies performed among the general population (ie, including men and women), only women were included, provided they had been analysed as a subgroup. Studies or study arms evaluating cookstoves that did not use solid biomass were not included.

Primary and secondary outcomes were selected based on their established associations with HAP and their relative contributions to the global burden of mortality and morbidity in the prenatal, paediatric and adult periods. ${ }^{3} 4-9$ 16-18 The primary

\begin{tabular}{|c|c|c|}
\hline \multirow[t]{2}{*}{$\begin{array}{l}\text { Prenatal } \\
\text { outcomes }\end{array}$} & $\begin{array}{l}\text { Primary } \\
\text { outcomes }\end{array}$ & $\begin{array}{l}\text { Low birth weight (birth weight }<2500 \mathrm{~g} \text { ) } \\
\text { Preterm birth (birth before } 37 \text { weeks of gestation) } \\
\text { Perinatal mortality (stillbirth+early neonatal mortality) }\end{array}$ \\
\hline & $\begin{array}{l}\text { Secondary } \\
\text { outcomes }\end{array}$ & $\begin{array}{l}\text { Small for gestational age (birth weight }<10 \text { th centile } \\
\text { for gestational age) } \\
\text { Stillbirth } \\
\text { Early neonatal mortality (death within } 7 \text { days after } \\
\text { birth) } \\
\text { Neonatal mortality (death within } 28 \text { days after birth) } \\
\text { Birth weight (continuous scale) } \\
\text { Gestational age (continuous scale) }\end{array}$ \\
\hline \multirow[t]{2}{*}{$\begin{array}{l}\text { Child } \\
\text { outcomes }\end{array}$} & $\begin{array}{l}\text { Primary } \\
\text { outcome }\end{array}$ & $\begin{array}{l}\text { Acute respiratory infections (ARIs) (including } \\
\text { pneumonia) }\end{array}$ \\
\hline & $\begin{array}{l}\text { Secondary } \\
\text { outcomes }\end{array}$ & $\begin{array}{l}\text { Otitis media with effusion } \\
\text { Wheezing/asthma (including exacerbations) } \\
\text { Conjunctivitis } \\
\text { Death due to respiratory disease } \\
\text { Chronic cough } \\
\text { Lung function outcomes (PEFR, } \mathrm{FEV}_{1,}, \mathrm{FVC}, \mathrm{FEV}_{1} / \mathrm{FVC} \text { ) } \\
\left.\text { HAP concentrations ( } \mathrm{PM}_{2.5^{\prime}} \mathrm{PM}_{10^{\prime}} \mathrm{CO}\right)\end{array}$ \\
\hline \multirow[t]{2}{*}{$\begin{array}{l}\text { Outcomes in } \\
\text { women }\end{array}$} & $\begin{array}{l}\text { Primary } \\
\text { outcome }\end{array}$ & COPD \\
\hline & $\begin{array}{l}\text { Secondary } \\
\text { outcomes }\end{array}$ & $\begin{array}{l}\text { Chronic cough } \\
\text { Chronic phlegm } \\
\text { ARIs (including pneumonia) } \\
\text { Wheezing/asthma (including exacerbations) } \\
\text { Death due to respiratory disease } \\
\text { Conjunctivitis } \\
\text { Lung function outcomes (PEFR, FEV } \mathrm{FVC}_{1}, \mathrm{FEV}_{1} / \mathrm{FVC} \text { ) } \\
\left.\text { HAP concentrations ( } \mathrm{PM}_{2.5}, \mathrm{PM}_{10}, \mathrm{CO}\right)\end{array}$ \\
\hline
\end{tabular}

$\mathrm{CO}$, carbon monoxide; HAP, household air pollution; PEFR, peak expiratory flow rate; PM, particulate matter.

and secondary pregnancy, child and women outcomes are listed in table 1.

\section{Information sources}

We carried out a systematic and comprehensive bibliographic search using electronic databases: PubMed, EMBASE, Google Scholar, WHO Global Health Library (in addition to MEDLINE covering African Index Medicus, LILACS, Index Medicus for the Eastern Mediterranean Region, Index Medicus for SouthEast Asia Region, Western Pacific Region Index Medicus, WHO Library Database and Scientific Electronic Library Online) and the Cochrane Central Register of Controlled trials for relevant published studies, and the WHO International Clinical Trials Registry Platform for unpublished studies. References and citations of each eligible study were also checked by hand for additional studies that met our eligibility criteria. An expert in the field was approached in an attempt to identify any additional eligible studies.

\section{Search}

The initial search was conducted on 22 February 2016 and was updated on 6 April 2018. Full electronic searches for each database are provided in web supplementary appendix pages $2-3$. No restrictions were imposed with regard to language in which the report was published or publication date.

\section{Study selection}

The selection process consisted of two rounds: a selection based on title and abstract, and then screening of full-text articles for eligibility. Two reviewers (MT and PAWN) independently 
performed the searches and assessed eligibility. The final selection was based on consensus, with arbitration by a third reviewer (JVB or OCPvS) in the case of disagreement.

\section{Data collection process}

Two reviewers independently extracted relevant data from eligible studies (MT and PAWN for (quasi-)experimental studies; JFK and EAB for longitudinal observational studies) using a customised form based on the Cochrane Public Health Group data extraction form. ${ }^{19}$ Extracted data items were cross-checked between the reviewers, with any disagreement being resolved through consensus or via arbitration by a third reviewer if necessary (JVB or OCPvS).

\section{Data items}

A comprehensive set of data items was extracted, including full reference, publication type, year of publication, setting (country, rural vs urban), study design, duration of the study, sample size, type of intervention, type of control, type of participants, outcomes (including definition and measurement level/location) and follow-up time.

\section{Risk of bias in individual studies}

Two reviewers independently assessed the risk of bias in individual studies (MT and PAWN for (quasi-)experimental studies; JFK and EAB for longitudinal observational studies) using the Effective Public Health Practice Project Quality Assessment Tool for Quantitative Studies. ${ }^{20}$ Any disagreement was resolved by consensus or by consulting a third reviewer if necessary (JVB or $\mathrm{OCPvS}$ ). Risk of bias was not used to determine eligibility of individual studies to be included in this review.

\section{Summary measures}

The following effect measures were extracted: numbers of participants with adverse outcomes by intervention allocation and corresponding ORs/risk ratios (RRs) for dichotomous outcomes; mean and SD and/or median and IQR for continuous outcomes within groups and corresponding between-group differences. Where possible, 95\% CIs were calculated for each measure if these had not been provided in the article. If relevant data items were missing from reports, authors were contacted to obtain these.

\section{Statistical analysis}

Main findings from the systematic review, including characteristics and key findings of individual studies, are presented in tabular form. Where possible, we combined data from individual studies in random-effects meta-analysis. If authors adjusted for confounders, we selected the effect estimates of the most adjusted model presented. Effect estimates from cluster RCTs were combined with those from non-clustered studies only when the cluster RCTs had been analysed at the individual level, with clustering having been accounted for. One study reported separate effect estimates for two regions ${ }^{21}$; these were pooled using meta-analysis prior to pooling with effect estimates from other studies. Heterogeneity across studies was assessed both qualitatively as well as quantitatively using $\mathrm{I}^{2}$ test. Due to the low number of studies in individual meta-analyses, $\mathrm{I}^{2}$ results were not used to assess whether meta-analysis was appropriate. Risk of bias across studies was assessed visually using funnel plots when at least 10 studies were available for an outcome. We prespecified to conduct subgroup analyses for children under 5 years of age, and according to whether cooking was done in a separate kitchen. In an attempt to minimise risk of bias introduced by study designs with limited potential for attributing causality, our primary analyses were conducted using only (quasi-)experimental studies. In a sensitivity analysis for the primary outcomes, we conducted separate meta-analyses also including any longitudinal observational studies. All analyses were done with Stata SE 14.

\section{RESULTS}

\section{Study selection and characteristics}

We screened 5195 records and identified 24 (quasi-)experimental and 29 longitudinal observational studies as eligible for inclusion in our review (figure 1). Five ongoing studies were identified (web supplementary appendix page 4). Study characteristics for (quasi-)experimental studies are provided in table 2 and for longitudinal observational studies in web supplementary appendix pages 5-14. Among the (quasi-)experimental studies, 21 were RCTs (six cluster RCTs), ${ }^{22-42}$ two were NRCTs $^{2143}$ and one was a CBA study. ${ }^{44}$ (Quasi-)experimental studies were conducted in rural areas across Asia, Africa and Central America: China $(\mathrm{n}=1),{ }^{44}$ Ghana $(\mathrm{n}=2),{ }^{24} 31$ Guatemala $(\mathrm{n}=9),{ }^{25} 28-3036-3943$ India $(\mathrm{n}=2),{ }^{26} 42$ Malawi $(\mathrm{n}=2),{ }^{27} 41$ Mexico $(n=3),{ }^{5} 3133$ Pakistan $(n=1),{ }^{21}$ Peru $(n=1),{ }^{40}$ Rwanda $(n=1)^{34}$ and Senegal $(n=2) .^{22}{ }^{23}$ Eight reports described findings from the RESPIRE trial in Guatemala, ${ }^{25} 28-30$ 36-39 three were part of the same RCT in Mexico 313335 and two reports from Senegal described the same data. ${ }^{22}$ All studies had traditional stove use as control group, including open fires, threestone stoves and brick, clay or coal stoves. The most common cookstove improvements were: better conservation of heat, optimised combustion centres and the addition of chimneys to vent smoke away (web supplementary appendix pages 15-16). Pregnancy outcomes were assessed in two studies, ${ }^{26}{ }^{39}$ child health outcomes in six studies 262836404143 and health outcomes among women in 16 studies. $^{21} 23-27293032-343638394243$ HAP was assessed at individual level in 14 studies ( 2 in children ${ }^{2836} ; 11$ in women $^{24252729-3236383942}$; and 1 in both women and children ${ }^{26}$ ) and at household level in 5 studies. 2131343644 The 29 longitudinal observational studies included in this review were carried out in rural settings across Latin America (11 studies), ${ }^{45-55}$ Asia (9 studies) $)^{56-64}$ and Africa (9 studies). ${ }^{65-73}$ Twenty-two were uncontrolled before-after studies, ${ }^{45-49} 51 \quad 53-56 \quad 58-61 \quad 63 \quad 65 \quad 66 \quad 68-73$ four were prospective cohort studies ${ }^{50526467}$ and three were retrospective cohort studies. ${ }^{57} 6162$ Additional details on the longitudinal observational studies are provided in web supplementary appendix pages 5-14.

\section{Risk-of-bias assessment}

Fourteen (quasi-)experimental studies were deemed to have a low risk of bias, nine had moderate and one had a high risk (web supplementary appendix pages 17-18). Among longitudinal observational studies, risk of bias was high for 4, moderate for 19 and low for 6 studies (web supplementary appendix pages 19-20).

\section{Impact of improved cookstoves on primary outcomes}

\section{Primary analyses using (quasi-)experimental studies}

Six (quasi-) experimental studies reported effect estimates for the primary outcomes (table 3). ${ }^{26} 353739-41$ All relevant cluster RCTs were analysed at the individual level and accounted for clustering; effect estimates could thus be combined with those from individual-level RCTs in meta-analyses. Among the primary outcomes, meta-analysis of (quasi-)experimental studies was only possible for paediatric acute respiratory infections (ARIs). There was no significant change in paediatric lower ARIs (including 

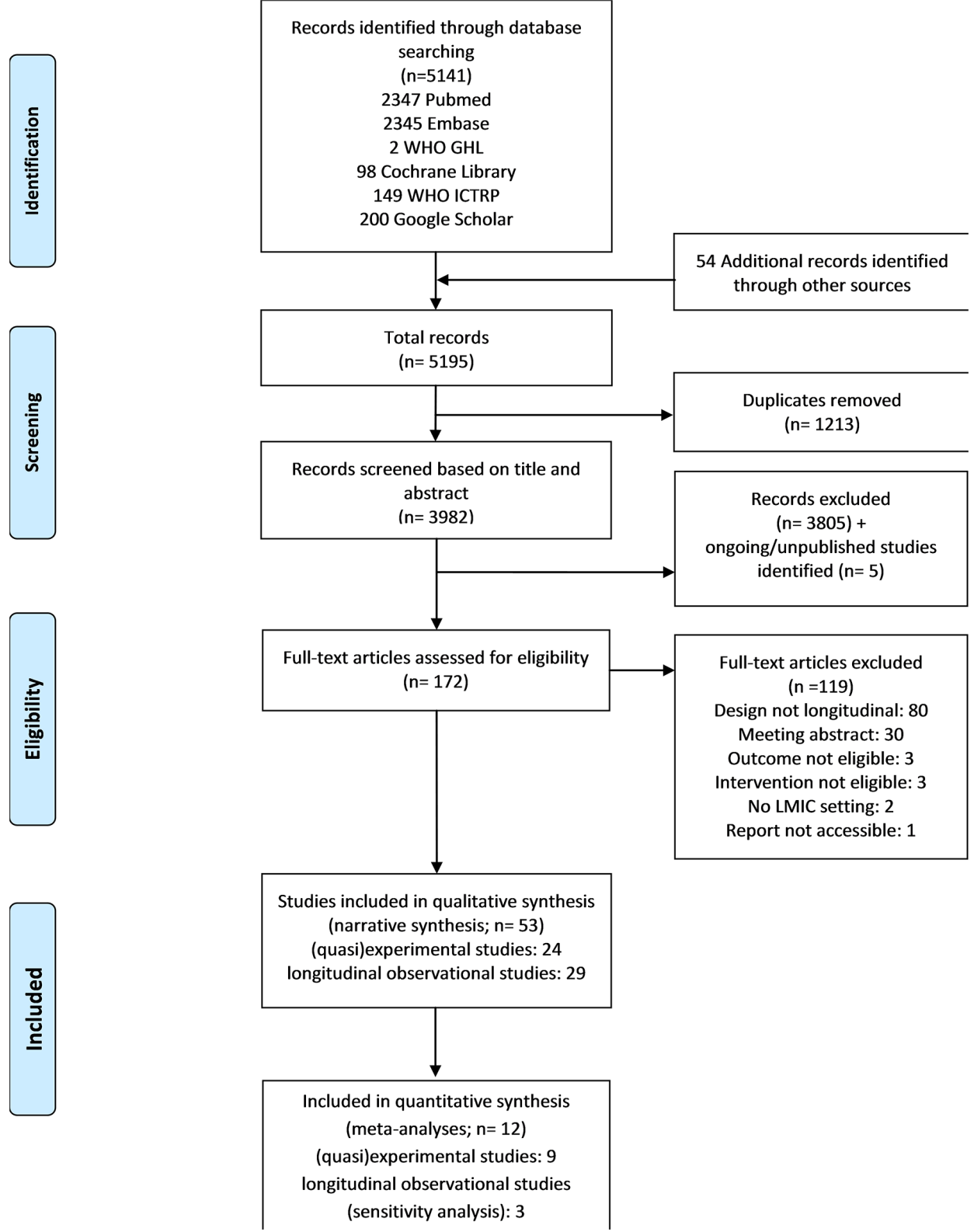

Figure 1 Preferred Reporting Items for Systematic Reviews and Meta-Analyses diagram outlining study selection. GHL, Global Health Library; ICTRP, International Clinical Trial Registry Platform; LMICs, low and middle income countries.

pneumonia; three studies, 11560 children; incidence rate ratio (IRR): 1.02 (95\% CI 0.84 to 1.24 ); figure $2 \mathrm{~A})^{374041}$ or in severe pneumonia in meta-analysis (two studies, 11061 children; IRR 0.88 (95\% CI 0.39 to 2.01 ); figure $2 \mathrm{~B}$ ). ${ }^{3741}$ In another study, improved cookstoves significantly decreased the duration of upper and lower respiratory infections (IRR 0.79 (95\% CI 0.70 to 0.89 ) and IRR 0.41 (95\% CI 0.21 to 0.80 ), respectively), with evidence of a dose-response relationship, with health impact in the intervention group being larger in households using mainly the improved cookstove versus those co-using the traditional cookstove. $^{35}$

No observable effects of cookstove improvements on LBW (174 babies; OR 0.74 (95\% CI 0.33 to 1.66$))^{39}$ or infant mortality, stillbirths and miscarriages (1176 babies; relative risk (RR) change $15 \%(95 \%$ CI -13 to 43$))^{26}$ were seen in individual studies. No (quasi-)experimental studies assessed the impact of improved cookstoves on preterm birth or COPD among women. One study described a trend towards reduction in 'respiratory system disease' among women responsible for cooking who were allocated an improved cookstove: RR 0.51 (95\% CI not reported, $\mathrm{P}=0.07$ ). ${ }^{23}$ This was defined as cough, wheezing and/or difficulty breathing, and may in part reflect COPD.

Sensitivity analyses using (quasi-)experimental and longitudinal observational studies

Consistent with our primary analyses, no significant impact of improved cookstoves on paediatric ARIs was observed in prespecified sensitivity analyses including findings from longitudinal observational studies (figure 3A and B). Improved cookstoves were, however, associated with a significant reduction in COPD among women when combining data from longitudinal observational studies: two studies, ${ }^{57} 649757$ participants; RR 0.74 (95\% CI 0.61 to 0.90 ; figure $3 \mathrm{C}$ ). 


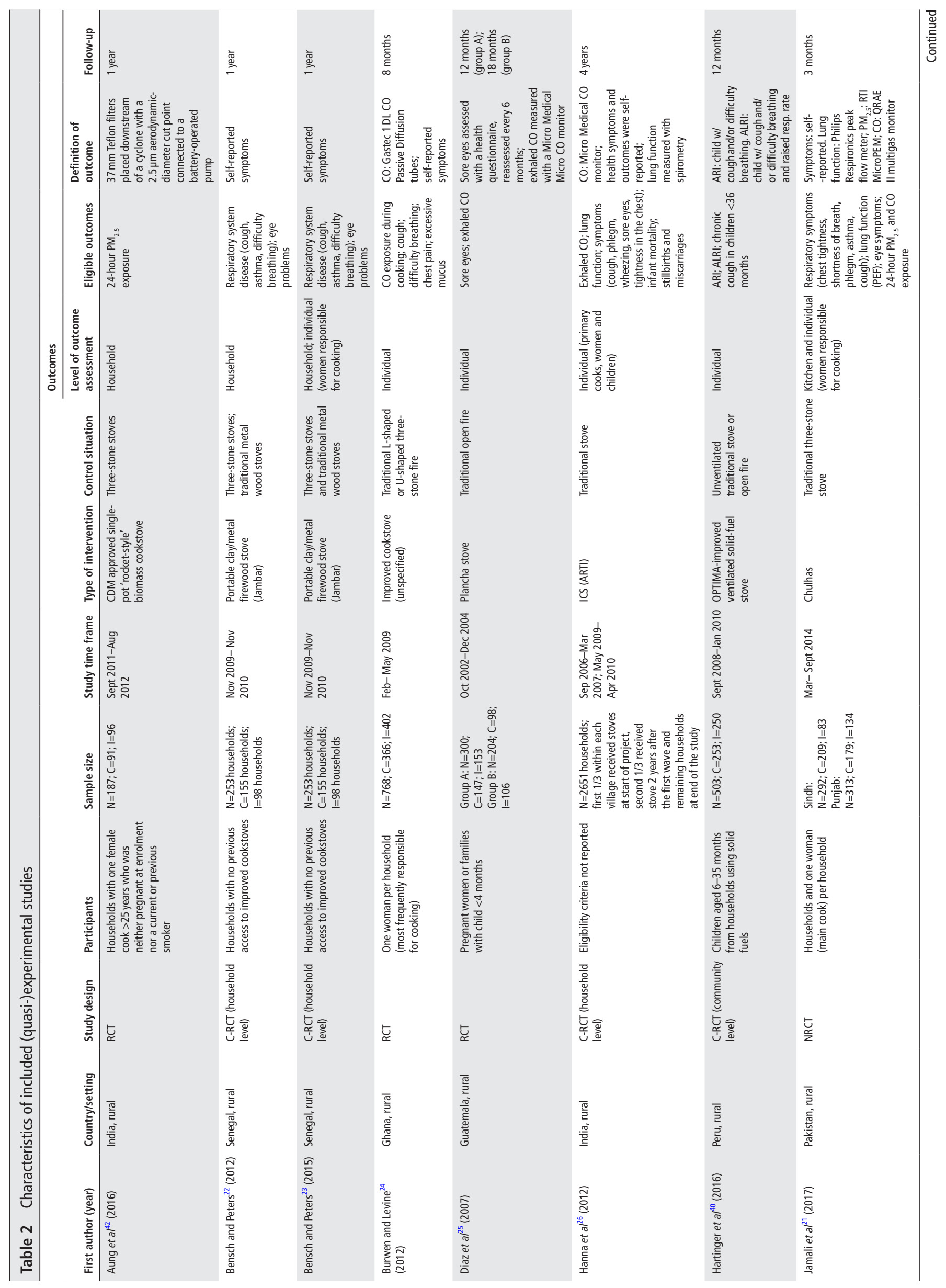

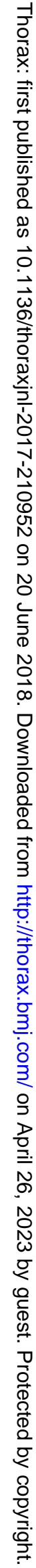




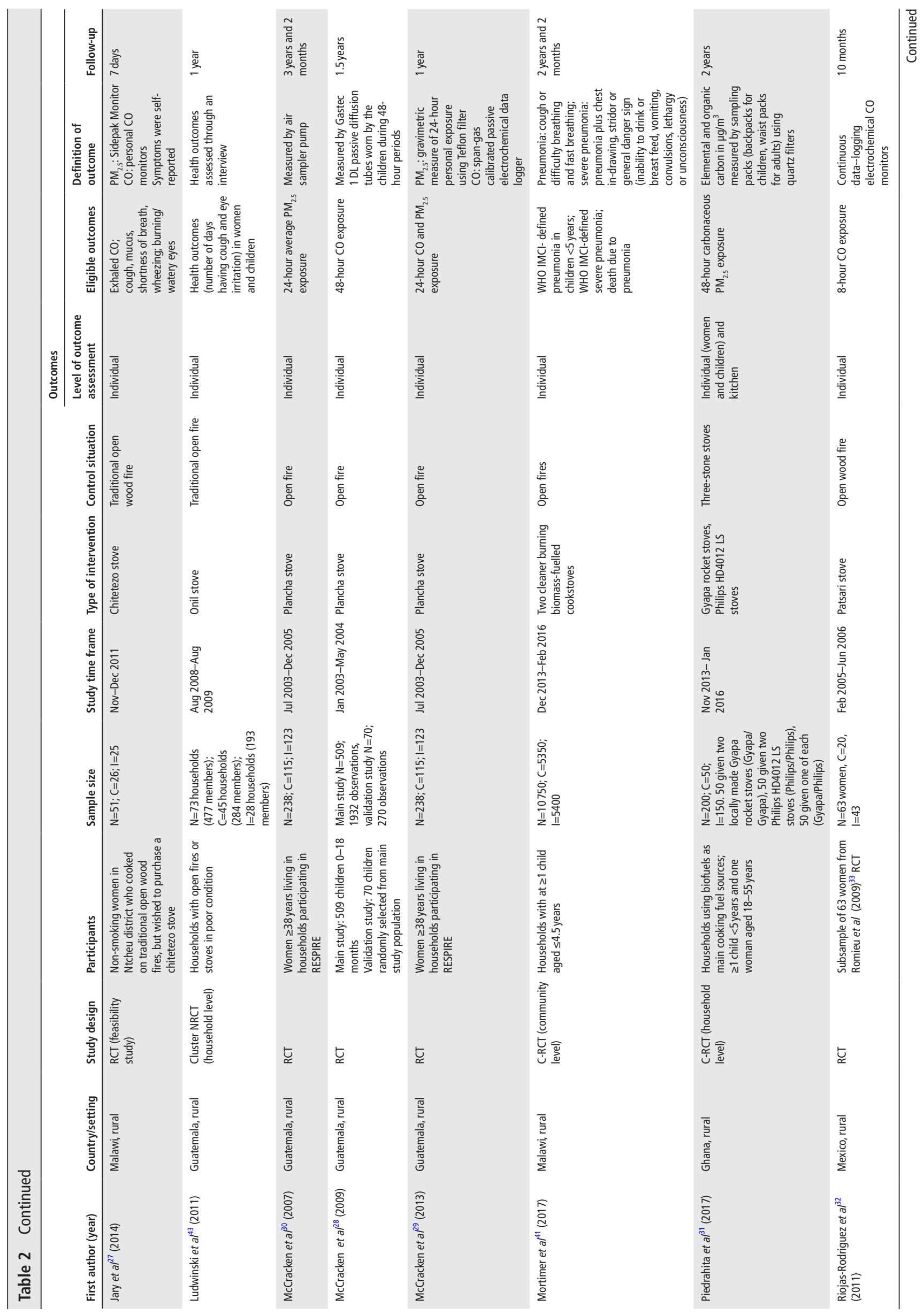




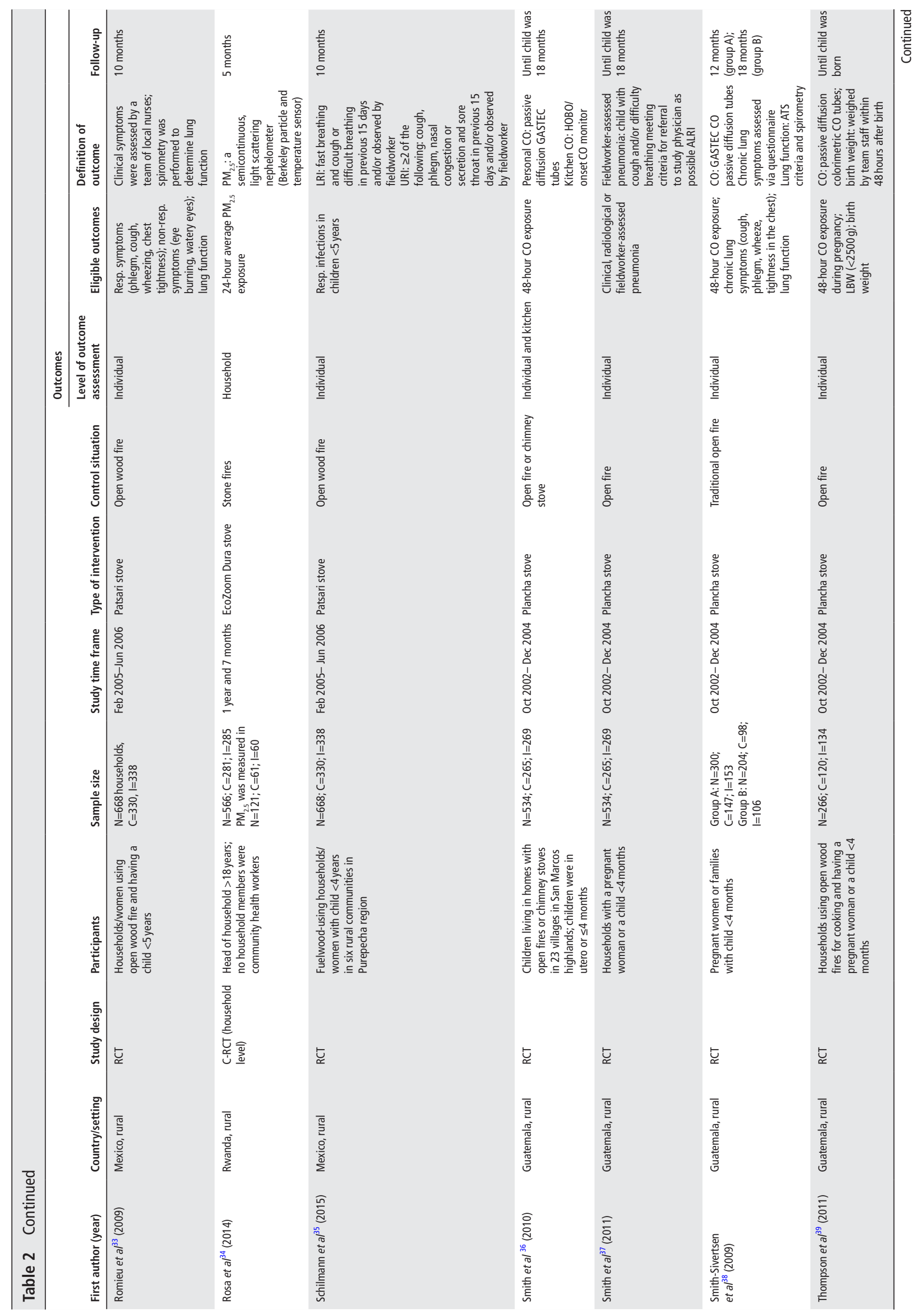

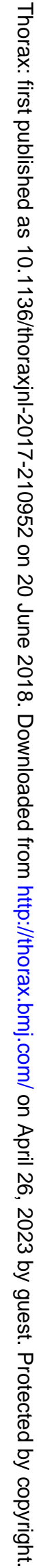




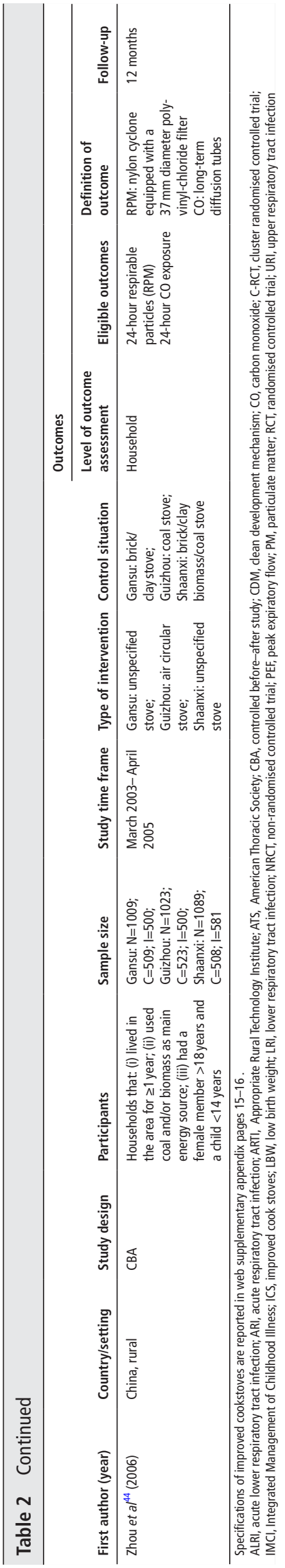

Impact of improved cookstoves on secondary outcomes

Analyses using (quasi-)experimental studies

Effect estimates from (quasi-)experimental studies for the secondary outcomes are shown in web supplementary appendix pages 21-28. Meta-analyses were possible for birth weight (continuous scale) and maternal respiratory and ocular symptoms. Improved cookstoves had no statistically significant impact on birth weight in meta-analysis (two studies, 694 babies; difference in means: $82 \mathrm{~g}(95 \% \mathrm{CI}-22$ to $185 \mathrm{~g}$; figure $4 \mathrm{~A}){ }^{26}{ }^{29}$ Meta-analyses indicated that, among women, improved cookstoves significantly reduced the incidence of cough (four studies $^{21} 242733$; 1779 participants; RR 0.72 (95\% CI 0.60 to 0.87; figure 4B)), phlegm (four studies 21242733 ; 1779 participants: RR 0.65 (95\% CI 0.52 to 0.80 ); figure 4C), wheezing/ breathing difficulty (four studies ${ }^{21} 242733$; 1779 participants: RR 0.41 (95\% CI 0.29 to 0.59); figure 4D) and conjunctivitis (three studies; 892 participants: RR 0.58 (95\% CI 0.43 to 0.78 ), figure 4E). ${ }^{21} 2633$

Other secondary outcomes were only described in individual studies or in ways that precluded meta-analyses to be performed. Improved cookstoves had no impact on child deaths due to respiratory disease in one study (IRR 0.76 (95\% CI 0.17 to 3.37$)$ ). ${ }^{41}$ No significant impact on cough incidence or duration was observed among children in three studies, 264043 although in a subgroup analysis a significant reduction in cough duration was observed among girls in one study. ${ }^{43} \mathrm{CO}$ exposure among children living in households with improved cookstoves was significantly decreased compared with controls in two reports from the same study (relative change in geometric means: $-0.52 \%(95 \% \mathrm{CI}$ -0.56 to -0.47$)) .^{28} 36$ The impact of improved cookstoves on lung function was reported in four studies. ${ }^{21} 263338$ Decline in $\mathrm{FEV}_{1}$ across the study period was significantly smaller in women using an improved cookstove as compared with controls in one study: difference in $\mathrm{FEV}_{1}$ decline $31 \mathrm{~mL} /$ year (95\% CI 7 to 55 ). ${ }^{33}$ In another study, the mean peak expiratory flow rate improved significantly among women in one out of two communities where improved cookstoves were introduced. ${ }^{21}$ Both studies assessing exhaled CO in women found significant reductions in those who had improved cookstoves. ${ }^{25} 27$ Two out of seven studies found significant reductions in personal CO exposure, ${ }^{3638}$ and one out of three in cooking area CO levels. ${ }^{34}$ All three studies assessing cooking area $\mathrm{PM}_{2.5}$ levels found significant reductions in the improved stove group. ${ }^{213134}$ Four out of five studies assessing changes in personal $\mathrm{PM}_{2.5}$ exposure found significant reductions in the intervention group. ${ }^{30-32} 34$ No studies assessing any of the other predefined secondary outcomes were identified.

\section{Findings from longitudinal observational studies}

Overall, findings from the longitudinal observational studies suggest that improved cookstoves are associated with reductions in adverse respiratory health outcomes: one study found significant reductions in paediatric pneumonia and severe pneumonia ${ }^{67}$; two of three studies that evaluated chronic respiratory diseases found statistically significant decreases among improved stove users ${ }^{576164}$; three out of six studies found significant improvements in lung function ${ }^{516465}$ and four out of six studies found significant decreases in self-reported respiratory symptoms. ${ }^{58}$ 65-67 Additionally, these studies provide evidence that improved cookstoves reduce HAP levels: 12 out of 17 studies found that improved cookstoves were associated with significantly decreased kitchen levels of PM pollutants, ${ }^{464749535459626369-7173}$ and 13 out of 17 studies found significant decreases in indoor CO levels among improved cookstove users. ${ }^{45-4749505459606369-7173}$ Three out of five studies 
Table 3 Primary outcomes of included (quasi-)experimental studies

\begin{tabular}{|c|c|c|c|c|}
\hline \multirow[b]{2}{*}{ First author (year) } & \multicolumn{2}{|l|}{ Events } & Effect measures & \multirow[b]{2}{*}{ Summary of findings } \\
\hline & Intervention & Control & OR/RR $(95 \% \mathrm{Cl})$ & \\
\hline \multicolumn{5}{|c|}{ Pregnancy and infant outcomes } \\
\hline \multicolumn{5}{|l|}{ Low birth weight (LBW) } \\
\hline Thompson et al $(2011)^{39}$ & n/N (\%): 13/69 (19\%) & n/N (\%): 26/105 (25\%) & OR $(95 \% \mathrm{Cl}): 0.74(0.33,1.66)$ & $\begin{array}{l}\text { There was no statistically significant difference in } \\
\text { LBW between infants born to mothers using wood- } \\
\text { fuelled chimney stoves and those born to mothers } \\
\text { using open fires }\end{array}$ \\
\hline \multicolumn{5}{|c|}{$\begin{array}{l}\text { Infant mortality, stillbirths and } \\
\text { miscarriages* }\end{array}$} \\
\hline Hanna et al $(2012)^{26}$ & $14.7 \%$ ( $\mathrm{N} / \mathrm{N}$ not reported) & $11.9 \%$ (n/N not reported) & $\begin{array}{l}\text { Relative risk change }(95 \% \mathrm{Cl}) \text { : } \\
15 \%(-13,43)\end{array}$ & $\begin{array}{l}\text { The study found no effect of randomly being } \\
\text { offered a stove on infant mortality, stillbirths and } \\
\text { miscarriages }\end{array}$ \\
\hline \multicolumn{5}{|l|}{ Children } \\
\hline \multicolumn{5}{|l|}{$\begin{array}{l}\text { Acute respiratory infections } \\
\text { (including pneumonia) }\end{array}$} \\
\hline Hartinger et al (2016) & $\begin{array}{l}\mathrm{N}=248 \\
\text { Number of ARI episodes: } 831 \\
\text { Number of ALRI episodes: } 25 / 554 \\
\text { (554 ARI episodes seen with } \\
\text { respiratory rate measurements) }\end{array}$ & $\begin{array}{l}\mathrm{N}=251 \\
\text { Number of ARI episodes: } 877 \\
\text { Total number of ALRI episodes: } \\
10 / 563 \\
\text { ( } 563 \mathrm{ARI} \text { episodes seen with } \\
\text { respiratory rate measurements) }\end{array}$ & $\begin{array}{l}\text { Number of } A R I \text { episodes } \\
\text { Relative rate }(95 \% \mathrm{Cl}): 0.95 \\
(0.82,1.10) \\
\text { Number of } A L R I \text { episodes } \\
\text { Relative rate }(95 \% \mathrm{Cl}): 2.47 \\
(0.84,7.29)\end{array}$ & $\begin{array}{l}\text { The study did not observe a reduction in paediatric } \\
\text { ARI and ALRI episodes among improved stove users }\end{array}$ \\
\hline Mortimer et al $(2017)^{41}$ & $\begin{array}{l}\text { Number of IMCl-defined pneumonia } \\
\text { episodes in the overall intention-to- } \\
\text { treat population: } 1255 / 5297 \\
\text { Incidence rate (cases per } 100 \\
\text { child-years) }(95 \% \mathrm{CI}): 15.76(14.89 \text {, } \\
16.63) \\
\text { Number of IMCl-defined severe } \\
\text { pneumonia episodes in the overall } \\
\text { intention-to-treat population: } \\
186 / 5297 \\
\text { Incidence rate (cases per } 100 \text { child- } \\
\text { years) }(95 \% \mathrm{CI}): 2.33(2.00,2.67)\end{array}$ & $\begin{array}{l}\text { Number of IMCI-defined pneumonia } \\
\text { episodes in the overall intention-to- } \\
\text { treat population: } 1251 / 5246 \\
\text { Incidence rate (cases per } 100 \\
\text { child-years) }(95 \% \mathrm{Cl}): 15.58(14.72 \text {, } \\
16.45) \\
\text { Number of IMCI-defined severe } \\
\text { pneumonia episodes in the overall } \\
\text { intention-to-treat population: } \\
145 / 5246 \\
\text { Incidence rate (cases per } 100 \text { child- } \\
\text { years) }(95 \% \mathrm{CI}): 1.80 \text { ( } 1.51,2.09)\end{array}$ & $\begin{array}{l}\text { IMCI-defined pneumonia IRR } \\
(95 \% \mathrm{CI}): 1.05(0.93,1.18) \\
\text { IMCI-defined severe pneumonia } \\
\text { IRR }(95 \% \mathrm{CI}): 1.30(0.99,1.71)\end{array}$ & $\begin{array}{l}\text { The study found no evidence that an intervention } \\
\text { comprising cleaner burning biomass-fuelled } \\
\text { cookstoves reduced the risk of pneumonia in young } \\
\text { children }\end{array}$ \\
\hline Schilmann et al $(2015)^{35}$ & $\mathrm{~N}=287$ (prevalence not reported) & N=272 (prevalence not reported) & $\begin{array}{l}\text { URI: } \\
\text { using mainly Patsari stove: OR } \\
(95 \% \mathrm{Cl}): 0.84(0.69,1.03) \\
\text { Combined use of Patsari and } \\
\text { traditional stoves: OR }(95 \% \mathrm{Cl}) \text { : } \\
0.93(0.76,1.18) \\
\text { LRI: } \\
\text { using mainly Patsari stove: OR } \\
\text { (95\% CI): } 0.61(0.21,1.81) \\
\text { Combined use of Patsari and } \\
\text { traditional stoves: OR }(95 \% \mathrm{Cl}) \text { : } \\
0.88(0.26,2.99)\end{array}$ & $\begin{array}{l}\text { There was no significant impact on the incidence } \\
\text { of respiratory infections among children of mothers } \\
\text { using mainly the Patsari stove. There was, however, a } \\
\text { reduction in the duration of both URIs and LRIs in } \\
\text { Patsari users (IRR }(95 \% \mathrm{CI}): 0.79(0.70,0.89) \text { and } \\
0.41(0.21,0.80) \text {, respectively) }\end{array}$ \\
\hline Smith et al $(2011)^{37}$ & 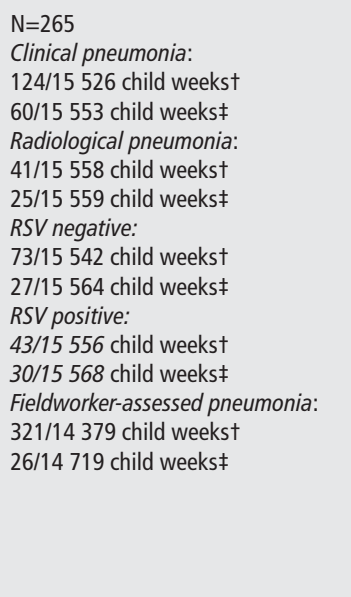 & 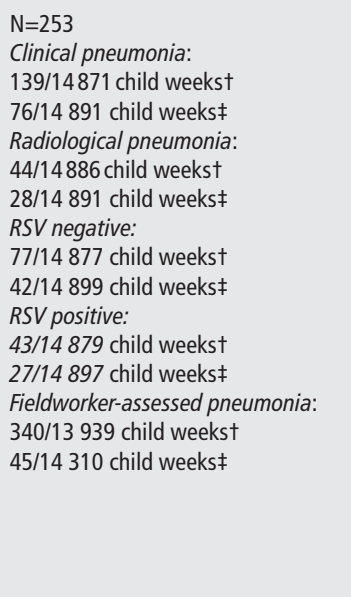 & 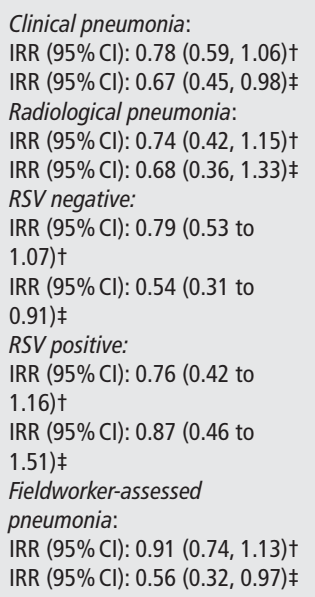 & $\begin{array}{l}\text { Implementation of chimney stoves did not } \\
\text { significantly impact the incidence of physician- } \\
\text { diagnosed pneumonia (any severity) for children } \\
\text { younger than } 18 \text { months. There were, however } \\
\text {, significant reductions in the intervention group for } \\
\text { severe fieldworker-assessed, physician-diagnosed } \\
\text { and RSV-negative pneumonia }\end{array}$ \\
\hline
\end{tabular}

${ }^{*}$ Broader definition than the one prespecified (perinatal mortality) in the protocol.

tAll cases of pneumonia.

$\ddagger$ Severe cases of pneumonia.

ALRI, acute lower respiratory tract infection; ARI, acute respiratory tract infection; IMCI, integrated management of illness; IRR, incidence rate ratio; LRI, lower respiratory infection; RR, risk ratio;

$R S V$, respiratory syncytial virus; URI, upper respiratoy infection. 


\section{A: paediatric acute lower respiratory tract infections}

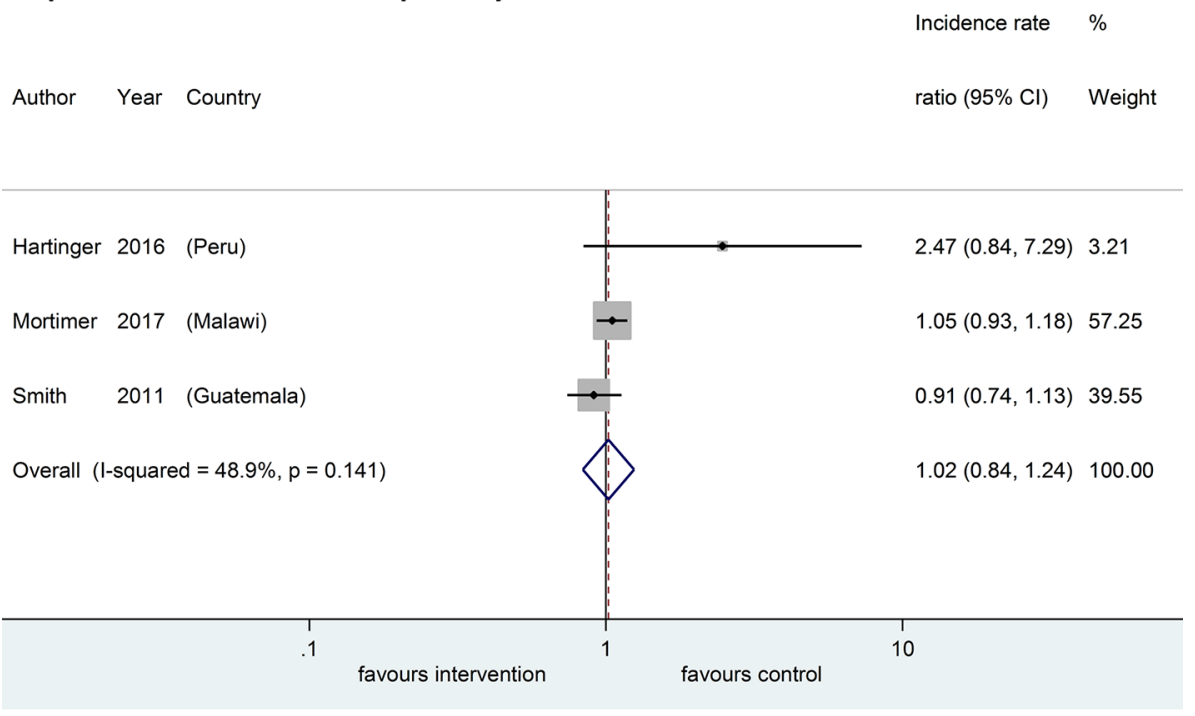

\section{B: paediatric severe pneumonia}

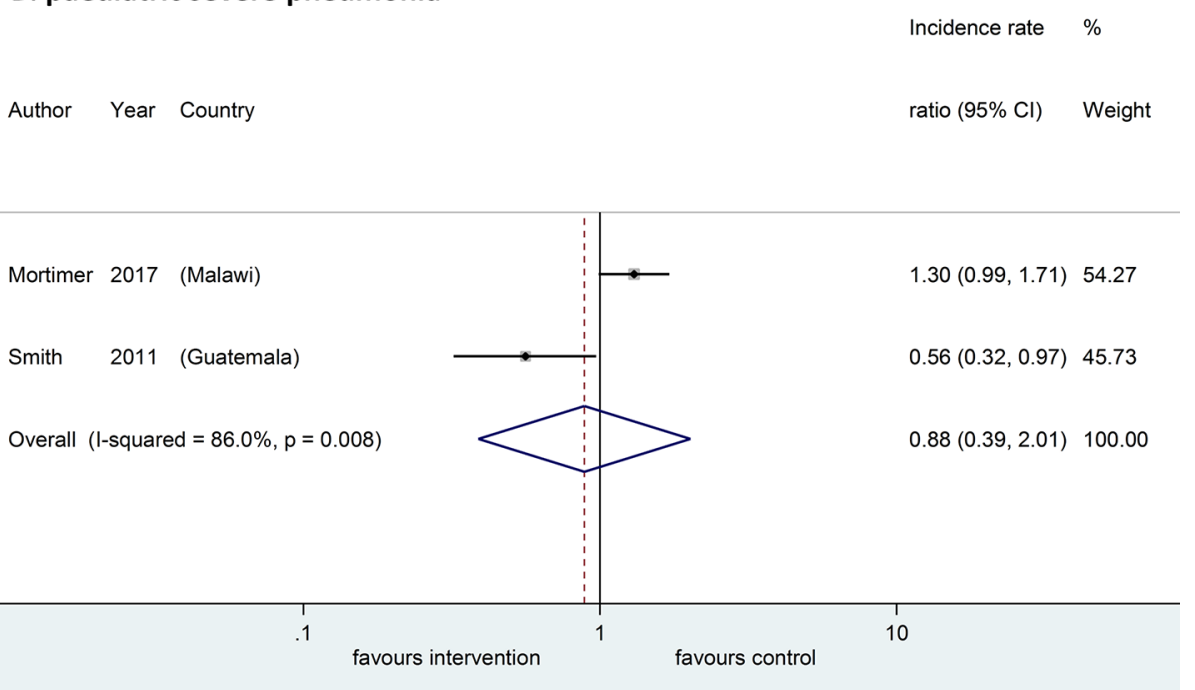

Figure 2 Meta-analyses of primary outcomes. (A) Acute lower respiratory tract infections in children and (B) severe pneumonia in children.

measuring PM levels, ${ }^{47} 4954$ and 11 out of 12 studies measuring CO levels, ${ }^{46-50} 54-56687173$ found statistically significant reductions in personal exposure among improved cookstove users.

\section{DISCUSSION}

Our systematic review provides mixed evidence regarding the impact of improved biomass cookstoves on health outcomes among women and children in LMICs. Few methodologically robust studies assessed our prespecified primary outcomes. Cookstove improvements had no demonstrable impact on child health outcomes in meta-analyses. No significant impact on adverse pregnancy outcomes was observed in individual studies, and no (quasi-)experimental studies assessing COPD among women were identified. In a prespecified sensitivity analysis, improved cookstoves were associated with a $26 \%$ reduction in the incidence of COPD among women. Meta-analyses of secondary outcomes among women further showed reductions in cough by $28 \%$, phlegm by $35 \%$, wheezing by $59 \%$ and conjunctivitis by $42 \%$. Many studies showed that improved cookstoves significantly reduced indoor $\mathrm{CO}$ and $\mathrm{PM}_{2.5}$ levels and exposure, which likely mediated the observed health benefits.

To our knowledge, this is the first meta-analysis assessing the impact of improved biomass cookstoves on women's and child health in LMICs. ${ }^{5} 1113$ Using a highly comprehensive search strategy as part of a prespecified review protocol, we identified 53 studies relevant to our research question. In our interpretation, we focused primarily on evidence derived from studies using the most robust designs as advocated by the EPOC group. ${ }^{15}$ There was considerable variation between studies in which outcomes were evaluated and how these were defined, measured and how effect estimates were expressed. Also, several included reports originate from the same studies, in particular many reports described various findings from a large-scale RCT conducted in rural Guatemala (RESPIRE). ${ }^{25}$ 29-31 36-39 These aspects eventually restricted the number of studies that could be combined in meta-analyses of individual outcomes, in particular of our predefined primary outcomes. For pragmatic reasons, we sometimes combined in meta-analyses outcomes which were slightly diverse but likely to assess the same concept 


\section{A: paediatric acute lower respiratory infections}

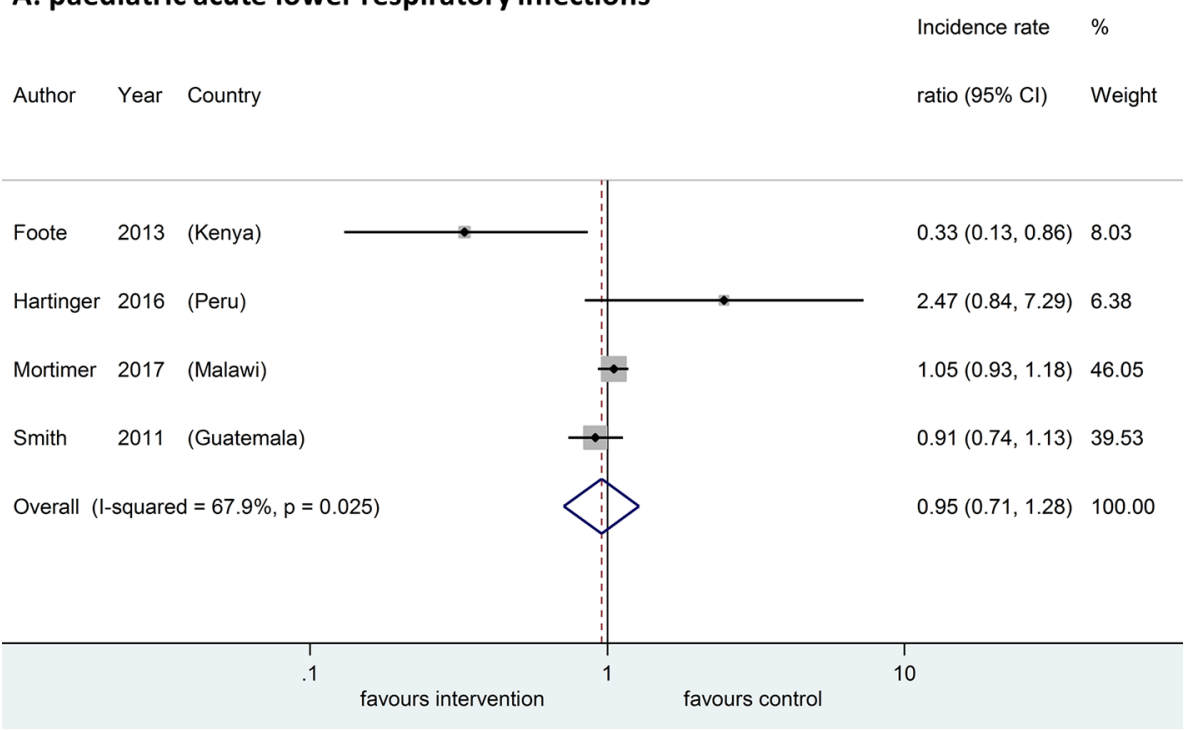

\section{B: paediatric severe pneumonia}

Incidence rate $\%$

Author Year Country

ratio $(95 \% \mathrm{Cl}) \quad$ Weight

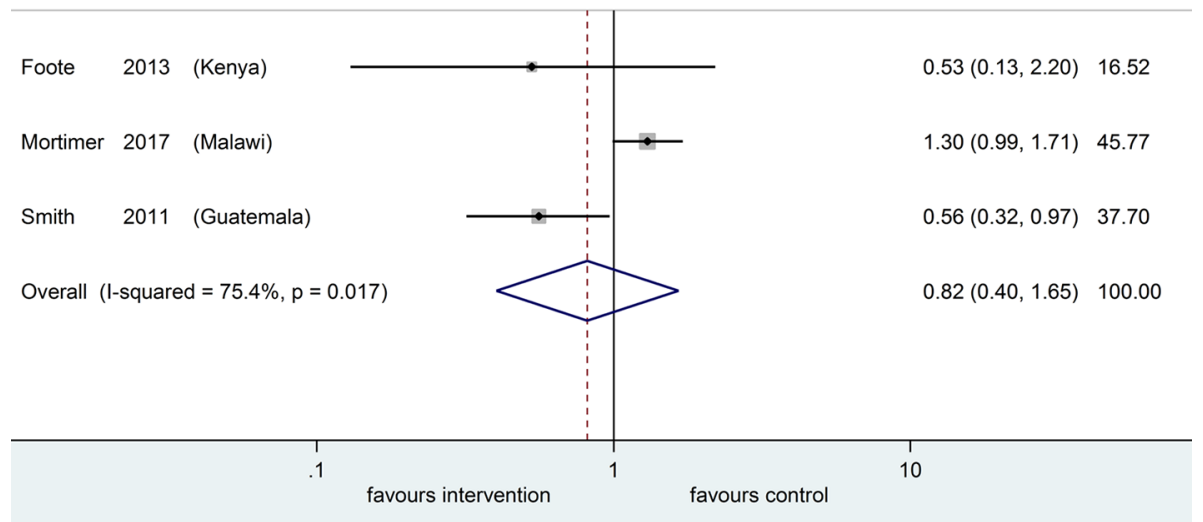

\section{C: COPD in women}

$\begin{array}{llr} & \text { Risk } & \% \\ \text { Author Year Country } & \text { ratio }(95 \% \mathrm{Cl}) & \text { Weight }\end{array}$

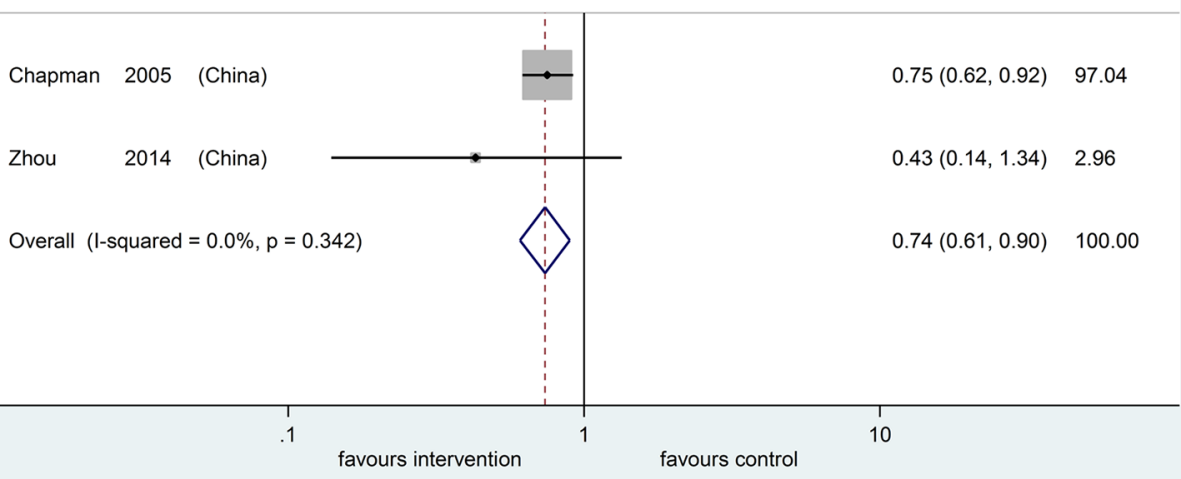

Figure 3 Sensitivity analyses of primary outcomes. (A) Acute lower respiratory tract infections in children; (B) severe pneumonia in children and (C) COPD in women. 


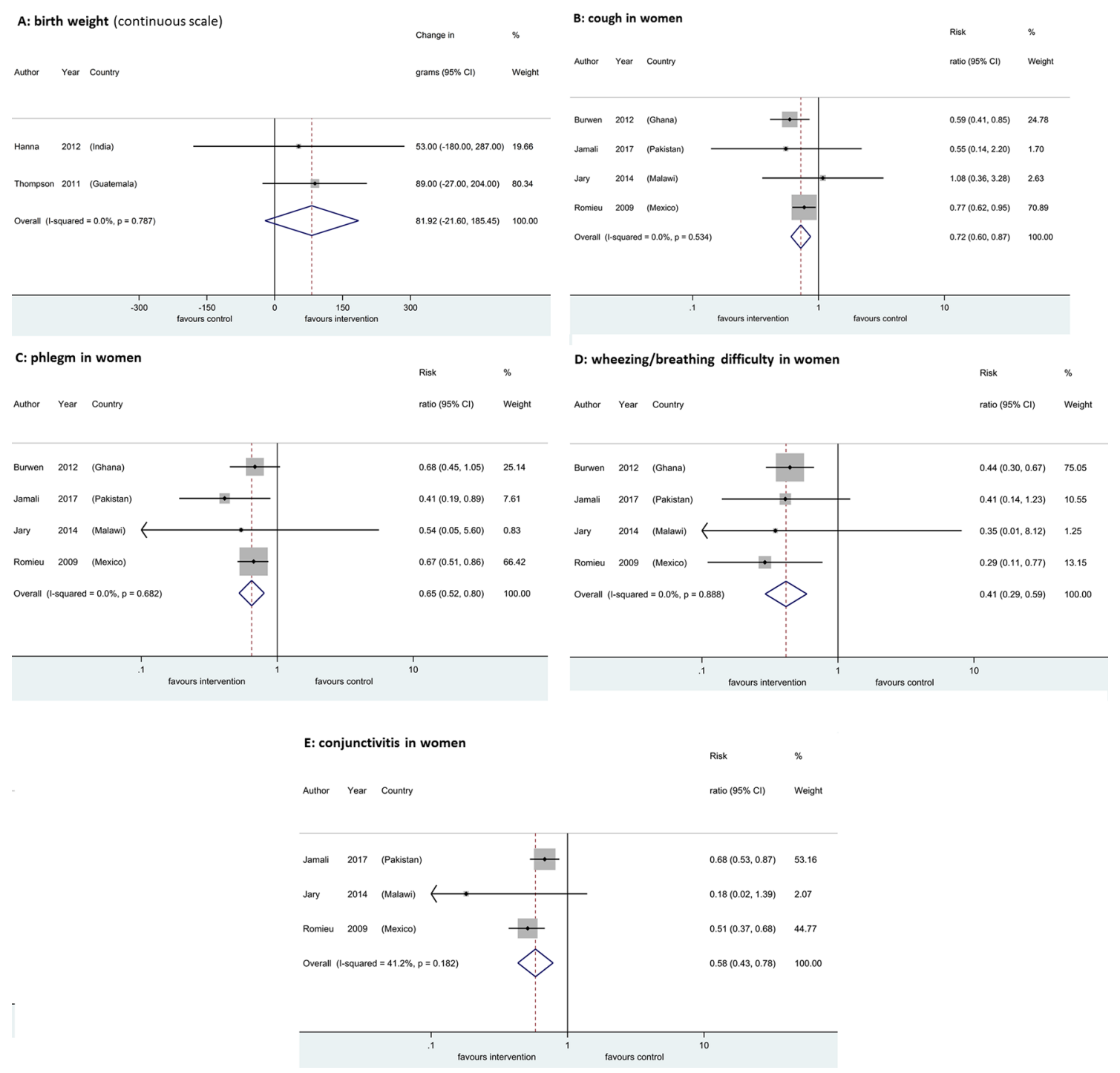

Figure 4 Meta-analyses of secondary outcomes. (A) Birth weight (continuous scale); (B) cough in women; (C) phlegm in women; (D) wheezing/ breathing difficulty in women and (E) conjunctivitis in women.

(eg, conjunctivitis and sore eyes; wheezing and/or breathing difficulty). Conducting meta-analyses with few studies is methodologically sound ${ }^{74} 75$; however, the findings should be interpreted with care and additional studies are needed-with several already being underway - to increase confidence in the effect estimates. It should furthermore be noted that our prespecified primary outcomes were often not the primary outcomes of individual studies and hence these studies and the meta-analyses combining them may have had limited power to assess the actual impact of the intervention. Follow-up time was likely too short in some studies to effectively assess health impact, whereas studies with longer term follow-up sometimes noted that the health impact waned off, as use of the improved cookstoves was not sustained. Ineffective and unsustained use of improved cookstoves affected outcomes from a number of studies and may have biased the findings towards the null, although at the same time these may be argued to reflect-to some extent-the realworld situation. Given the low number of studies that could be combined in meta-analysis, we were unable to assess the relative effectiveness of the different cookstoves or cookstove improvements. Likewise, there were too few studies to allow for our predefined subgroup analyses by age group and cooking location to be conducted.

We are aware of two previous systematic reviews assessing the impact of improved biomass cookstoves on HAP indicators. ${ }^{13}{ }^{14}$ Meta-analyses from one review indicated significant reductions in personal PM exposure and kitchen CO and PM concentrations, but were not performed for health outcomes. ${ }^{14}$ These HAP improvements are in line with our systematic review findings, where many studies reported positive findings in terms of HAP reduction. Similar to Thomas and colleagues, ${ }^{13}$ we experienced that variations in measurement location, expression of between-group differences and study set-up precluded pooling of HAP indicators in meta-analyses. We identified a greater number of eligible studies assessing the health impact of improved biomass cookstoves than previous reviews despite applying narrower study selection criteria, ${ }^{13}{ }^{14}$ making meta-analysis of health indicators possible for the first time. This is important because, contrary to Quansah and colleagues who based on their qualitative review conclude that 'current standalone household air pollution interventions yield little if any health benefit ${ }^{14}$ findings from our meta-analyses in fact suggest 
that improved biomass cookstoves provide significant symptom relief and potential health benefits among women. Importantly, no adverse effects were identified. Ongoing work is thus needed to locally develop, tailor, evaluate, implement and upscale effective cookstove improvement programmes in close collaboration with end-users. Experiences from earlier programmes across the globe have generated transferrable lessons in terms of which are the main facilitators and barriers to uptake of improved biomass cookstoves and these should be taken into account when designing local programmes. ${ }^{13} 1476$ Likewise, a clear understanding of what enables or precludes sustained use of the improved stoves can help maximise long-term health benefits. Platforms such as the online HAP Intervention Tool enable policy-makers to estimate the potential health benefits of stove improvements locally, taking aspects such as acceptability and sustained use into account. ${ }^{77}$

Several knowledge gaps remain in understanding the health impact of improved cookstoves. Whereas many studies have evaluated their impact on HAP indicators, more work is needed to quantify the potential health benefits. In addition to evaluating health symptoms and short-term benefits, more studies should investigate long-term health impact. Significant reductions in COPD and lung cancer mortality among women were identified in studies in this review, ${ }^{57} 6164$ indicating that the potential health gain may indeed be substantial. Also, more work is needed on evaluating whether improved biomass cookstoves may help reduce adverse pregnancy outcomes. Comparative studies are required to study which particular cookstoves or cookstove improvements (eg, stoves, more efficient combustion) are most effective, and more studies should take into account cost-effectiveness. It should furthermore be noted that no studies in urban areas were identified by our search. By 2030, an estimated five billion people will live in urban areas, of which two billion will live in slums in LMICs, mainly in Africa and Asia. ${ }^{78}$ Many differences exist between rural and urban settings, for example, regarding cooking location (eg, in the possibilities to cook outside) and background environmental air pollution. It is therefore essential that the existing knowledge gap of the potential health impact of improved cookstoves in urban-in particular slum-areas is filled in future research. ${ }^{79}$

From both the health and the environmental perspective, switching from using solid fuels for cooking to using cleaner fuels would be preferred over using improved cookstoves for solid biomass combustion. ${ }^{10}$ However, as pointed out earlier, financial and infrastructural constraints will likely hamper the transition to cleaner fuel options in the near future. ${ }^{10}$ Meanwhile, improved cookstoves can help temporarily and cost-effectively reduce some of the health risks associated with cooking using biomass. ${ }^{12}$ The consistent signal of symptom reduction and the potential health benefit observed among women in our meta-analyses suggest that future studies should move away from using control groups without intervention, at least in rural areas in LMICs. Rather, we suggest that outside the urban context, where randomised studies are still needed, implementation and upscaling studies including quasi-experimental evaluations may be a more appropriate approach to identify context-specific barriers and facilitators in developing culturally appropriate, locally relevant implementation while evaluating and expanding the associated health benefits to wider populations.

\section{CONCLUSION}

Improved biomass cookstoves had no demonstrable impact on child health but reduce airway symptoms and conjunctivitis, and potentially also COPD incidence, among women in LMICs. Considering that billions of people continue to rely on biomass combustion for cooking over the next decades, improved biomass cookstoves may help realise population health gains among women in LMICs pending the transition to using cleaner fuels.

Acknowledgements We thank Gunther Bensch, Jason Burwen, Esperanza Diaz, Daniel Pope and Rufus Edwards for providing additional information about their studies. We thank Daan Nieboer for statistical support.

Contributors MT and PAWN performed electronic searches and study selection, extracted data and performed risk-of-bias assessment for (quasi-)experimental studies and wrote the first version of the manuscript. EAB and JFK extracted data and performed risk-of-bias assessment for longitudinal observational studies and assisted in updating electronic searches and study selection. TF checked the extracted data and performed meta-analyses. GRB co-wrote the manuscript. OCPvS and JVB supervised the various stages of the study and writing of the manuscript. All authors were involved in designing the study and interpreting the findings and have read and approved the final version of the manuscript.

Funding GRB is supported by an Intermediate Fellowship by the Wellcome Trust DBT India Alliance (Clinical and Public Health Research Fellowships). JVB is supported by fellowships from the Netherlands Lung Foundation (4.2.14.063J0) and the Erasmus MC

Competing interests None declared.

Patient consent Not required.

Provenance and peer review Not commissioned; externally peer reviewed.

Data sharing statement Full data set and statistical codes are available from the corresponding author.

(c) Article author(s) (or their employer(s) unless otherwise stated in the text of the article) 2018. All rights reserved. No commercial use is permitted unless otherwise expressly granted.

\section{REFERENCES}

1 International Energy Agency. World energy outlook 2016. Paris: International Energy Agency, 2016.

2 Smith KR, Bruce N, Balakrishnan K, et al. Millions dead: how do we know and what does it mean? Methods used in the comparative risk assessment of household air pollution. Annu Rev Public Health 2014;35:185-206.

3 Gordon SB, Bruce NG, Grigg J, et al. Respiratory risks from household air pollution in low and middle income countries. Lancet Respir Med 2014;2:823-60.

4 Forouzanfar MH, Afshin A, Alexander LT, et al. GBD 2015 Risk Factors Collaborators. Global, regional, and national comparative risk assessment of 79 behavioural, environmental and occupational, and metabolic risks or clusters of risks, 19902015: a systematic analysis for the Global Burden of Disease Study 2015. Lancet 2016;388:1659-724.

5 Lee A, Adobamen PR, Agboghoroma 0, et al. Household air pollution: a call to action. Lancet Respir Med 2015;3:e1-2.

6 Rehfuess E. Fuel For Life: Household Energy and Health. Geneva: World Health Organization, 2006

7 Bruce NG, Dherani MK, Das JK, et al. Control of household air pollution for child survival: estimates for intervention impacts. BMC Public Health 2013;13:S8.

8 Amegah AK, Quansah R, Jaakkola JJ. Household air pollution from solid fuel use and risk of adverse pregnancy outcomes: a systematic review and meta-analysis of the empirical evidence. PLoS One 2014;9:e113920

9 Patelarou E, Kelly FJ. Indoor exposure and adverse birth outcomes related to fetal growth, miscarriage and prematurity-a systematic review. Int J Environ Res Public Health 2014;11:5904-33.

10 Watts N, Adger WN, Ayeb-Karlsson S, et al. The Lancet Countdown: tracking progress on health and climate change. Lancet 2017:389:1151-64.

11 Amegah AK, Jaakkola JJ. Household air pollution and the sustainable development goals. Bull World Health Organ 2016;94:215-21.

12 Mehta S, Shahpar C. The health benefits of interventions to reduce indoor air pollution from solid fuel use: a cost-effectiveness analysis. Energy for Sustainable Dev 2004;8:53-9.

13 Thomas $\mathrm{E}$, Wickramasinghe $\mathrm{K}$, Mendis $\mathrm{S}$, et al. Improved stove interventions to reduce household air pollution in low and middle income countries: a descriptive systematic review. BMC Public Health 2015;15:650.

14 Quansah R, Semple S, Ochieng CA, et al. Effectiveness of interventions to reduce household air pollution and/or improve health in homes using solid fuel in lowand-middle income countries: A systematic review and meta-analysis. Environ Int 2017; 103:73-90 
15 Cochrane Effective Practice and Organisation of Care Review Group. What study designs should be included in an EPOC review and what should they be called? https://epoc.cochrane.org/sites/epoc.cochrane.org/files/uploads/EPOC $\% 20$ Study\% 20Designs\%20About.pdf (accessed 25 Jul 2017).

16 GBD 2015 DALYs and HALE Collaborators. Global, regional, and national disabilityadjusted life-years (DALYS) for 315 diseases and injuries and healthy life expectancy (HALE), 1990-2015: a systematic analysis for the Global Burden of Disease Study 2015. Lancet 2016;388:1603-58.

17 GBD 2015 Disease and Injury Incidence and Prevalence Collaborators. Global, regional, and national incidence, prevalence, and years lived with disability for 310 diseases and injuries, 1990-2015: a systematic analysis for the Global Burden of Disease Study 2015. Lancet 2016;388:1545-602.

18 GBD 2015 Mortality and Causes of Death Collaborators. Global, regional, and national life expectancy, all-cause mortality, and cause-specific mortality for 249 causes of death, 1980-2015: a systematic analysis for the Global Burden of Disease Study 2015. Lancet 2016;388:1459-544.

19 The Cochrane Public Health Group. Data Extraction and Assessment Template. https://ph.cochrane.org/sites/ph.cochrane.org/files/public/uploads/CPHG\%20Data\% 20extraction\%20template 0.docx (accessed 25 Jul 2017).

20 Effective Public Health Practice Project (EPHPP). Quality Assessment Tool for Quantitative Studies. http://www.ephpp.ca/PDF/Quality\%20Assessment\%20Tool_ 2010_2.pdf (accessed July 25, 2017).

21 Jamali T, Fatmi Z, Shahid A, et al. Evaluation of short-term health effects among rural women and reduction in household air pollution due to improved cooking stoves: quasi experimental study. Air Qual Atmos Health 2017;10:809-19.

22 Bensch G, Peters J. A Recipe for Success? Randomized free distribution of improved cooking stoves in Senegal. SSRN Electronic Journal 2012.

23 Bensch G, Peters J. The intensive margin of technology adoption - Experimental evidence on improved cooking stoves in rural Senegal. J Health Econ 2015;42:44-63.

24 Burwen J, Levine DI. A rapid assessment randomized-controlled trial of improved cookstoves in rural Ghana. Energy for Sustainable Development 2012;16:328-38.

25 Diaz E, Smith-Sivertsen T, Pope D, et al. Eye discomfort, headache and back pain among Mayan Guatemalan women taking part in a randomised stove intervention trial. J Epidemiol Community Health 2007;61:74-9.

26 Hanna R, Duflo E, Greenstone M. Up in smoke: the influence of household behavior on the long-run impact of improved cooking stoves. NBER Working Paper No. 18033. 2012 https://www.hks.harvard.edu/m-rcbg/heep/papers/hanna_dp41.pdf (accessed 25 July 2017).

27 Jary HR, Kachidiku J, Banda $\mathrm{H}$, et al. Feasibility of conducting a randomised controlled trial of a cookstove intervention in rural Malawi. Int J Tuberc Lung Dis 2014;18:240-7.

$28 \mathrm{McCracken}$ JP, Schwartz J, Bruce N, et al. Combining individual-and group-level exposure information: child carbon monoxide in the Guatemala woodstove randomized control trial. Epidemiology 2009;20:127-36.

29 McCracken JP, Schwartz J, Diaz A, et al. Longitudinal relationship between personal $\mathrm{CO}$ and personal PM2.5 among women cooking with woodfired cookstoves in Guatemala. PLoS One 2013:8:e55670.

30 McCracken JP, Smith KR, Díaz A, et al. Chimney stove intervention to reduce long-term wood smoke exposure lowers blood pressure among Guatemalan women. Environ Health Perspect 2007;115:996-1001

31 Piedrahita R, Kanyomse E, Coffey E, et al. Exposures to and origins of carbonaceous PM 2.5 in a cookstove intervention in Northern Ghana. Sci Total Environ 2017:576:178-92.

32 Riojas-Rodriguez H, Schilmann A, Marron-Mares AT, et al. Impact of the improved patsari biomass stove on urinary polycyclic aromatic hydrocarbon biomarkers and carbon monoxide exposures in rural Mexican women. Environ Health Perspect 2011;119:1301-7

33 Romieu I, Riojas-Rodríguez H, Marrón-Mares AT, et al. Improved biomass stove intervention in rural Mexico: impact on the respiratory health of women. Am J Respir Crit Care Med 2009;180:649-56.

34 Rosa G, Majorin F, Boisson S, et al. Assessing the impact of water filters and improved cook stoves on drinking water quality and household air pollution: a randomised controlled trial in Rwanda. PLoS One 2014;9:e91011.

35 Schilmann A, Riojas-Rodríguez H, Ramírez-Sedeño K, et al. Children's Respiratory Health After an Efficient Biomass Stove (Patsari) Intervention. Ecohealth 2015; 12:68-76

36 Smith KR, McCracken JP, Thompson L, et al. Personal child and mother carbon monoxide exposures and kitchen levels: methods and results from a randomized trial of woodfired chimney cookstoves in Guatemala (RESPIRE). J Expo Sci Environ Epidemiol 2010;20:406-16.

37 Smith KR, McCracken JP, Weber MW, et al. Effect of reduction in household air pollution on childhood pneumonia in Guatemala (RESPIRE): a randomised controlled trial. Lancet 2011:378:1717-26.

38 Smith-Sivertsen T, Díaz E, Pope D, et al. Effect of reducing indoor air pollution on women's respiratory symptoms and lung function: the RESPIRE Randomized Trial, Guatemala. Am J Epidemiol 2009;170:211-20.

39 Thompson LM, Bruce N, Eskenazi B, et al. Impact of reduced maternal exposures to wood smoke from an introduced chimney stove on newborn birth weight in rural Guatemala. Environ Health Perspect 2011;119:1489-94.
40 Hartinger SM, Lanata CF, Hattendorf J, et al. Improving household air, drinking water and hygiene in rural Peru: a community-randomized-controlled trial of an integrated environmental home-based intervention package to improve child health. Int J Epidemiol 2016:45:dyw242-99.

41 Mortimer K, Ndamala CB, Naunje AW, et al. A cleaner burning biomass-fuelled cookstove intervention to prevent pneumonia in children under 5 years old in rural Malawi (the Cooking and Pneumonia Study): a cluster randomised controlled trial. Lancet 2017:389:167-75.

42 Aung TW, Jain G, Sethuraman K, et al. Health and climate-relevant pollutant concentrations from a carbon-finance approved cookstove intervention in rural India. Environ Sci Technol 2016:50:7228-38.

43 Ludwinski D, Moriarty K, Wydick B. Environmental and health impacts from the introduction of improved wood stoves: evidence from a field experiment in Guatemala. Environment, Development and Sustainability 2011;13:657-76.

44 Zhou Z, Jin Y, Liu F, et al. Community effectiveness of stove and health education interventions for reducing exposure to indoor air pollution from solid fuels in four Chinese provinces. Environmental Res Lett 2006;1:014010.

45 Alexander D, Linnes JC, Bolton S, et al. Ventilated cookstoves associated with improvements in respiratory health-related quality of life in rural Bolivia. J Public Health 2014;36:460-6.

46 Clark ML, Bachand AM, Heiderscheidt JM, et al. Impact of a cleaner-burning cookstove intervention on blood pressure in Nicaraguan women. Indoor Air 2013;23:105-14

47 Fitzgerald C, Aguilar-Villalobos M, Eppler AR, et al. Testing the effectiveness of two improved cookstove interventions in the Santiago de Chuco Province of Peru. Sci Total Environ 2012:420:54-64.

48 Guarnieri M, Diaz E, Pope D, et al. Lung Function in Rural Guatemalan Women Before and After a Chimney Stove Intervention to Reduce Wood Smoke Exposure: Results From the Randomized Exposure Study of Pollution Indoors and Respiratory Effects and Chronic Respiratory Effects of Early Childhood Exposure to Respirable Particulate Matter Study. Chest 2015;148:1184-92.

49 Li Z, Sjödin A, Romanoff LC, et al. Evaluation of exposure reduction to indoor air pollution in stove intervention projects in Peru by urinary biomonitoring of polycyclic aromatic hydrocarbon metabolites. Environ Int 2011;37:1157-63.

50 Northcross A, Chowdhury Z, McCracken J, et al. Estimating personal PM2.5 exposures using $\mathrm{CO}$ measurements in Guatemalan households cooking with wood fuel. J Environ Monit 2010;12:873-8.

51 Rennert WP, Porras Blanco RM, Muniz GB. The effects of smokeless cookstoves on peak expiratory flow rates in rural Honduras. J Public Health 2015;37:455-60.

52 Riojas-Rodríguez H, Romano-Riquer P, Santos-Burgoa C, et al. Household firewood use and the health of children and women of Indian communities in Chiapas, Mexico. Int J Occup Environ Health 2001;7:44-53.

53 Zuk M, Rojas L, Blanco S, et al. The impact of improved wood-burning stoves on fine particulate matter concentrations in rural Mexican homes. J Expo Sci Environ Epidemiol 2007;17:224-32

54 Cynthia AA, Edwards RD, Johnson M, et al. Reduction in personal exposures to particulate matter and carbon monoxide as a result of the installation of a Patsari improved cook stove in Michoacan Mexico. Indoor Air 2008;18:93-105.

55 Eppler AR, Fitzgerald C, Dorner SC, et al. Using exhaled carbon monoxide and carboxy-hemoglobin to evaluate the effectiveness of a chimney stove model in Peru. Int J Occup Environ Health 2013;19:325-31.

56 Balakrishnan K, Sambandam S, Ghosh S, et al. Household Air Pollution Exposures of Pregnant Women Receiving Advanced Combustion Cookstoves in India: Implication for Intervention. Ann Glob Health 2015;81:375-85

57 Chapman RS, He X, Blair AE, et al. Improvement in household stoves and risk of chronic obstructive pulmonary disease in Xuanwei, China: retrospective cohort study. BMJ 2005;331:1050.

58 Cheng Y, Kang J, Liu F, et al. Effectiveness of an Indoor Air Pollution (IAP) Intervention on Reducing IAP and Improving Women's Health Status in Rural Areas of Gansu Province, China. Open Journal of Air Pollution 2015;04:26-37.

59 Chengappa C, Edwards R, Bajpai R, et al. Impact of improved cookstoves on indoor air quality in the Bundelkhand region in India. Energy Sustain Dev 2007:11:33-44

60 Dutta K, Shields KN, Edwards R, et al. Impact of improved biomass cookstoves on indoor air quality near Pune, India. Energy Sustain Dev 2007;11:19-32.

61 Hosgood HD, Chapman R, Shen M, et al. Portable stove use is associated with lowe lung cancer mortality risk in lifetime smoky coal users. Br J Cancer 2008;99:1934-9.

62 Lan Q, Chapman RS, Schreinemachers DM, et al. Household stove improvement and risk of lung cancer in Xuanwei, China. J Nat/ Cancer Inst 2002;94:826-35.

63 Singh A, Tuladhar B, Bajracharya K, et al. Assessment of effectiveness of improved cook stoves in reducing indoor air pollution and improving health in Nepal. Energy Sustain Dev 2012:16:406-14.

64 Zhou Y, Zou Y, Li X, et al. Lung function and incidence of chronic obstructive pulmonary disease after improved cooking fuels and kitchen ventilation: a 9-year prospective cohort study. PLoS Med 2014;11:e1001621.

65 Critchley K, Teather K, Hughes $\mathrm{H}$, et al. Air quality, respiratory health and wood use for women converting from low-to high-efficiency stoves in rural Kenya. WIT Transactions on Ecology and the Environment 2015;198:205-16. 
66 Ezzati M, Kammen DM. Evaluating the health benefits of transitions in household energy technologies in Kenya. Energy Policy 2002;30:815-26.

67 Foote EM, Gieraltowski L, Ayers T, et al. Impact of locally-produced, ceramic cookstoves on respiratory disease in children in rural western Kenya. Am J Trop Med Hyg 2013;88:132-7.

68 Gitonga S, Nyaga J, Owalla $\mathrm{H}$, et al. Reducing indoor air pollution in rural households in Kenya. The ITDG Smoke and Health project 1998-2001. https://practicalaction.org/ docs/advocacy/smoke-project-report-kenya.pdf (accessed July 25, 2017).

69 Oluwole O, Ana GR, Arinola GO, et al. Effect of stove intervention on household air pollution and the respiratory health of women and children in rural Nigeria. Air Qual Atmos Health 2013;6:553-61.

70 Pennise D, Brant S, Agbeve SM, et al. Indoor air quality impacts of an improved wood stove in Ghana and an ethanol stove in Ethiopia. Energy Sustain Dev 2009;13:71-6.

71 Pilishvili T, Loo JD, Schrag S, et al. Effectiveness of Six Improved Cookstoves in Reducing Household Air Pollution and Their Acceptability in Rural Western Kenya. PLoS One 2016;11:e0165529.

72 Ochieng C, Vardoulakis S, Tonne C. Household air pollution following replacement of traditional open fire with an improved rocket type cookstove. Sci Total Environ 2017:580:440-7.
73 Yip F, Christensen B, Sircar K, et al. Assessment of traditional and improved stove use on household air pollution and personal exposures in rural western Kenya. Environ Int 2017;99:185-91.

74 loannidis JPA, Patsopoulos NA, Rothstein HR. Reasons or excuses for avoiding metaanalysis in forest plots. BMJ 2008;336:1413-5.

75 Borenstein $M$, Hedges LV, Higgins JP, et al. When does it make sense to perform a meta-analysis? Introduction to meta-analysis. New York: Wiley, 2009.

76 Rehfuess EA, Puzzolo E, Stanistreet D, et al. Enablers and barriers to large-scale uptake of improved solid fuel stoves: a systematic review. Environ Heath Perspect 2014;122:120-30.

77 Pillarisetti A, Mehta S, Smith KR. HAPIT the Household Air Pollution Intervention Tool, to evaluate the health benefits and cost-effectiveness of clean cooking interventions. Broken pumps and promises. Basel: Springer, 2016.

78 Ezeh A, Oyebode 0, Satterthwaite D, et al. The history, geography, and sociology of slums and the health problems of people who live in slums. Lancet 2017;389:547-58.

79 Thakur M, Boudewijns EA, Babu GR, et al. Low-smoke chulha in Indian slums: study protocol for a randomised controlled trial. BMC Public Health 2017;17:454. 